\title{
Reseña \\ weser \\ Bonanno, Alessandro, Francisco Martínez y Gilberto Aboites. 2016. El neoliberalismo, un momento de la globalización. Ciudad de México: Editorial Fontamara.
}

Vicente German-Soto ${ }^{1}$ onanno, Martínez Gómez y Aboites Manrique hacen una magistral contribución al estudio y entendimiento de la globalización y el neoliberalismo. A través de un conciso recorrido por los principales exponentes del pensamiento contemporáneo, por las teorías centrales y las múltiples posiciones ideológicas, en un lenguaje fluido y sin abuso de tecnicismos o términos difíciles de entender, los autores muestran que el actual proceso de desarrollo mundial en el que predominan, desde hace ya varias décadas, una desaceleración generalizada de las tasas de crecimiento, un deterioro notable de los salarios reales, mayor desempleo, aumento de la desigualdad, tiene explicación y origen en el momento conocido como neoliberalismo, una forma de manifestación de la globalización.

Desde la revisión bibliográfica realizada se percibe a la globalización como una parte intrínseca al capitalismo, mientras que el neoliberalismo es un aspecto transitorio, por lo que la globalización neoliberal es solo una manifestación de una representación socio-política mucho más amplia.

Es un libro cuya lectura permite entender los acontecimientos actuales trascendentales, como la reciente crisis mundial de 2008-2009, su origen y las razones que llevan periódicamente a estos infortunados sucesos. Es un texto que recomiendo a los estudiantes y profesionales del área de ciencias sociales porque el trabajo subyacente en esta obra aclara el panorama de la nada fácil tarea de comprender los acontecimientos sociales, políticos y económicos contemporáneos. En este sentido, el libro constituye un esquema conceptual para que investigaciones relacionadas a esta temática se desarrollen con la lógica y el sentido de la ubicación dentro del espectro del conocimiento. Por lo general, en la metodología de la ciencia se nos suele enseñar a cimentar la información que permita estimar un modelo teórico, de acuerdo a mecanismos básicos, y obtenemos resultados, pero muchas de las veces no asimilamos por qué o con qué fin la relación entre un conjunto de variables constituye evidencia del rumbo que llevan ciertos 
acontecimientos globales. Y ello es así porque al centrar la mirada en un tema en particular concentramos la atención en el árbol y, por tanto, se pierde de vista el bosque. Esta es la clase de ganancia intelectual que deja el presente volumen: al explicar las tendencias globales hace ver el bosque, pero a su vez permite enriquecer las conclusiones sobre el árbol. Es un libro escrito desde la óptica de las ciencias sociales, no desde la perspectiva separada de la Economía, la Historia y la Sociología, sino desde la simbiosis de estas disciplinas que en alguna época constituyeron un único cuerpo teórico para explicar los fenómenos sociales. Debido a esta característica es que resulta atractiva su lectura, ya que para describir la realidad contemporánea los autores salen del bosque, dejan de mirar el árbol, para dar un paseo desde el cual se puede divisar el bosque. Esta particularidad metodológica tiene dos ventajas, por lo menos. Primero, permite al lector observar hacia dónde va el mundo, sin los intrincados detalles que opacan el camino; permite ver las tendencias, las formas y las manifestaciones de los procesos globales. Segundo, posiciona al lector en el entendimiento de las fuerzas que gobiernan la sociedad. Aclara el significado profundo de los acontecimientos que emergen a la superficie y que como tales suelen a veces enredar, distraer de su verdadera intención. Por eso es que el libro es muy recomendable no solo a los académicos, sino también a todo aquel interesado en entender el actual modelo de producción mundial.

En esta obra, los autores tejen una vigorosa red de evidencias en la elaboración del argumento central de cómo la caída de la rentabilidad del capital desde los años sesentas suscitó una serie de crisis económicas, sociales y políticas en todo el mundo que dio origen al neoliberalismo, como una estrategia de reinserción y fortalecimiento de la globalización. Se deduce de la revisión de teorías y diversos pensamientos ideológicos que el capital busca recuperar la rentabilidad que venía desdibujándose durante la edad de oro del crecimiento mundial, una etapa de gran progreso relacionada con el afianzamiento del fordismo como modelo de producción.

El contenido está dividido en ocho capítulos, cuya ordenación claramente deja entrever la aplicación del método científico en la exposición, desarrollo y conclusión de los argumentos centrales. Inicia con una discusión de las definiciones y teorías básicas de la globalización y, posteriormente, en el capítulo 2, se centra en el modelo conocido como fordismo. Aquí la idea es que el fordismo al ser una etapa de producción que favoreció al trabajo y la productividad mundial se constituye en una razón determinante que da paso al neoliberalismo, ya que por el contrario, para el capital esta forma de producción afectó negativamente la tasa de beneficios. Esta explicación brota espontáneamente de las teorías clásicas del neoliberalismo discutidas en el capítulo tercero. En el capítulo cuarto se analiza el papel representado por los tres agentes principales de los sistemas económicos: el Estado, la empresa y el trabajador. En los capítulos cinco, seis y siete se estudia el nacimiento, evolución y crisis de la globalización neoliberal y de cómo el proceso de financiarización se constituyó en el eje que sostiene a la globalización en su modalidad "neoliberal". Finalmente, el capítulo ocho recoge las principales conclusiones en las que predictivamente los autores consideran habrá una continuación de la globalización, pero sin el neoliberalismo, ya que la globalización neoliberal implica una crisis estructural de la cual será difícil que escape.

Las condiciones impuestas por la política neoliberal han traído como consecuencia un aumento de la ganancia pero no del desarrollo regional, ha creado una situación de debilidad de la fuerza de trabajo que contrasta con la fortaleza exhibida durante el fordismo. Ante todo esto, ¿qué vamos hacer?, ¿qué rumbo tomará la sociedad?, ¿cuál es el papel de la ciencia y la tecnología?, ¿tendrá continuidad el neoliberalismo? Quizá lo más razonable es fraguar un nuevo proceso de acumulación que, como el fordismo, al 
- Revista de Ciencias Sociales y Humanidades. ISSN-P: 0188-9834 ISSN-E:2395-8669.

elevar la productividad, privilegie los salarios de los trabajadores y se retorne a tasas otra vez elevadas de crecimiento incluyente, no excluyente, como el actual. Pero suena más a buenos deseos que a una opción real, al menos en el corto plazo. Los autores dejan un vacío al respecto, no aventuran alguna predicción. Estas y otras cuestiones tienen un hilo conductor, sin embargo, es deber de los lectores buscar en "El neoliberalismo, un momento de la globalización" la hipótesis más razonable. 